\title{
Health related quality of life in patients with actinic keratosis - an observational study of patients treated in dermatology specialist care in Denmark
}

\author{
Gunnel Ragnarson Tennvall ${ }^{1 *}$, J.M. Norlin' ${ }^{1}$ I. Malmberg ${ }^{2}$, A.M. Erlendsson ${ }^{3}$ and M. Hædersdal ${ }^{3}$
}

\begin{abstract}
Background: Actinic keratosis (AK) is a common skin condition that may progress to non-melanoma skin cancer (NMSC). The disease may influence Health Related Quality of Life (HRQoL), but studies of HRQoL in patients with AK are limited.

The purpose of the study was to analyze HRQoL in patients with different severity levels of AK treated in dermatology specialist care using generic and disease-specific HRQoL instruments and to analyze their relationship.

Methods: AK patients who visited dermatological clinics in Denmark were included in an observational, cross-sectional, study in a multi-center setting. Dermatologists assessed AK severity and patients completed: Actinic Keratosis Quality of Life Questionnaire (AKQoL), Dermatology Life Quality Index (DLQI), and EQ-5D-5 L including EQ-VAS. Differences between categorical subgroups were tested with Wilcoxon rank-sum test. The relationship between instruments was analyzed with the Spearman correlation test.

Results: A total of 312 patients were included in the analyses. Patients reported impairment in the disease specific HRQoL instrument AKQoL (mean AKQoL 6.7, DLQI 2, EQ-5D-5 L 0.88, and EQ-VAS 79). HRQoL was least affected in patients with mild actinic disease, whereas patients with severe actinic damage suffered from further impaired HRQoL (mean AKQoL 10.1 and DLQI 4.6). Correlations between DLQI and AKQoL were moderate, whereas the correlations between DLQI and EQ-5D-5 $L$ and between AKQoL and EQ-5D-5 L were weak.

Conclusions: Patients with severe actinic damage showed more impairment in HRQoL than those with mild disease. Correlations between instruments suggest that they are complementary as they measure different aspects of HRQOL and are used for different purposes.
\end{abstract}

Keywords: Actinic keratosis, Health related quality of life, EQ-5D, DLQI, AKQoL

\section{Background}

Actinic keratosis (AK) is a common skin condition associated with cumulative sun exposure. AK lesions possess the risk of progressing to squamous cell carcinoma (SCC) [1-3], which is a common form of non-melanoma skin cancer (NMSC). Whereas AK lesions may regress spontaneously [4], persons who previously suffered from AK have an increased risk of developing new lesions [5]. The

\footnotetext{
* Correspondence: grt@ihe.se

${ }^{1} \mathrm{IHE}$, The Swedish Institute for Health Economics, P.O. Box 2127, SE-220 02 Lund, Sweden

Full list of author information is available at the end of the article
}

prevalence of AK varies considerably and has been estimated to between 1.4 and $25 \%$ of the population [5-9]. In elderly people, in countries with higher ultra violet radiation, and in patients receiving immunosuppressive treatments, such as organ transplant recipients, the prevalence is higher [10].

AKs typically present as red, scaly lesions on visible, sunexposed skin areas, such as face scalp and dorsal hands, thus often causing cosmetic discomfort. In addition, AKlesions may itch, bleed, and adhere to clothing and due to its pre-malignant nature patients may fear the risk of developing skin cancer. The presence of AK-lesions may thus
Ciomed Central

(c) 2015 Tennvall et al. This is an Open Access article distributed under the terms of the Creative Commons Attribution License (http://creativecommons.org/licenses/by/4.0) which permits unrestricted use, distribution, and reproduction in any medium, provided the original work is properly credited. The Creative Commons Public Domain Dedication waiver (http:// creativecommons.org/publicdomain/zero/1.0/) applies to the data made available in this article, unless otherwise stated. 
influence affected persons' well-being because of cosmetic reasons, locally hampering symptoms, and also due to fear of developing skin cancer. Studies including patient reported outcome measures and health related quality of life (HRQoL) is increasingly used in clinical practice and in clinical trials in dermatology [11]. Information about HRQoL is requested both by clinicians and reimbursement agencies [12, 13]. Information is limited on the potential impact of AKs, its accompanying symptoms and treatments, on patients' HRQoL [14-17].

There are several instruments available to investigate HRQoL in dermatology. Generic HRQoL instruments are used for a variety of diseases, which makes it possible to compare the burden of different medical conditions. The EuroQoL five-dimensional questionnaire (EQ-5D) is a generic preference-based instrument, which can be used to calculate quality-adjusted life years (QALYs). QALYs are important in health-economic evaluations and requested by reimbursement authorities [18]. It is recommended to use both generic and disease specific instruments in studies to capture different aspects of HRQoL [19-21]. The EuroQoL Visual Analogue Scale (EQ-VAS) is part of the EQ-5D questionnaire and it measures patient's overall self-rated health status.

Dermatology-specific or disease-specific instruments include aspects of the HRQoL that may not be captured by a generic instrument. Disease-specific instruments are more responsive to disease activity and treatment outcome and are therefore often used to reflect the patient perspective in clinical trials and observational research.

The Dermatology Life Quality Index (DLQI) is widely used in dermatology, both in clinical practice and in research $[22,23]$ and it has recently been used in patients with AK [24]. The questions in the DLQI focus on physical limitations, rather than psychological impact of skin diseases.

Recently, the Actinic Keratosis Quality of Life Questionnaire (AKQoL) was developed [14]. This questionnaire reflects how sun-damaged skin affects HRQoL and has the primary focus on psychological aspects.

The objective of the study was to analyze HRQoL in patients with different severity levels of AK treated in dermatology specialist care using generic and disease-specific HRQoL instruments and to analyze their relationship.

\section{Methods}

\section{Study set-up}

This is an observational cross-sectional multi-center study with focus on clinical patient characteristics and patient reported outcome measures. Data was collected at three university hospital clinics and seven private dermatology clinics in three geographic regions (Zealand, Funen and Jutland) in Denmark. AK patients $\geq 18$ years who visited the clinics during one specific week in May/June in 2012 were included.

\section{Ethics, consent and permissions}

The study was carried out after obtaining approval from The Danish Data Protection Agency. All persons gave their informed consent prior to inclusion in the study.

\section{Data collection}

Patients were asked to complete three separate HRQoL questionnaires i) AKQoL, ii) DLQI and iii) EQ-5D with 5 response levels (EQ-5D-5 L), including EQ-VAS.

Information was collected about educational level, employment, civil status and the following chronic comorbidities; asthma or chronic obstructive pulmonary disease; heart or vascular disease; diabetes; gastro-intestinal disease; cancer; joint disease (e.g. osteoarthritis, rheumatoid arthritis); physical disability or other chronic disease.

In order to characterize the severity of actinic damage, physicians collected information about previous and current AK lesions. Presence of AK was evaluated separately in nine anatomical regions (scalp, ears, face, chest, trunk, arm, hand, leg and foot), and for each AK-affected region, the following was registered: lesion count, lesion thickness, presence of field-cancerization, clinical suspicion of NMSC and selected treatment(s). Lesion count was estimated and categorized as 1, 2-4, 5-20, or $>20$ lesions per area. AK-thickness was graded from I-III according to Olsen et al. [25]. Field cancerization was classified as mild, moderate or severe, based on the clinical presentation of surrounding skin and included mottled erythema and pigmentation, telangiectasia, sallowness, laxity, and dry skin texture, without fulfilling the definition of AK. In the present study, 'Severe Actinic Damage' was defined as an anatomical area with $>5$ lesions, dominated by grade II-III AKs with moderate to severe field cancerization. Consequently, 'Mild actinic damage' was defined as an anatomical area with a single grade I AK without field cancerization. Treatment and disease characteristics were the focus in a separate publication [26].

\section{Patient reported outcome measures of health related quality of life}

AKQoL is an AK specific HRQoL questionnaire including 9 questions with one single global item and three subscales/domains: function, emotions and control [14]. The questionnaire is reflecting personal daily life, personal view of quality of life, social life, emotional life and control of life [14]. Each question is scored on a 4-point scale: A lot/all the time (scores 3), Quite a lot/often (scores 2), Some/sometimes (scores 1), Rarely/not at all (scores 0 ). In case only one question is incomplete, the missing value is designated a score of zero and the patient is included in the analysis [14]. A total score ranging from zero to a 
maximum of 27 is calculated by summing the score of each question. The higher the score, the more severe is the HRQoL impairment. The AKQoL includes the three domains Function, Emotions, and Control, which are summarized into one single Global item.

DLQI is a dermatology-specific instrument that relates to how the skin disease has affected the life of the patient over the past 7 days [23]. The questionnaire consists of 10 questions in 6 dimensions: 1) Symptoms and feelings, 2) Daily activities, 3) Leisure, 4) Work and school, 5) Personal relationships, and 6) Treatment. Each question has 4 alternative answers: "not at all", "a little", "a lot" and "very much", scored 0, 1, 2 and 3, respectively. The overall score aggregates the score of each question. DLQI ranges from 0 to 30, where a higher score represents more severe HRQoL impairment.

EQ-5D is a generic HRQoL instrument. The questionnaire includes five dimensions, mobility, self-care, usual activities, pain/discomfort, and anxiety/depression [27]. The Danish version of the EQ-5D-5 L was used in the study. The EQ-5D-5 L questionnaire has the same structure as the traditional three level questionnaire (EQ-5D$3 \mathrm{~L}$ ), but with five response levels: no problems, slight problems, moderate problems, severe problems and unable to/extreme problems. Each combination of responses is associated with utility values or relative weighting, which are often derived from previous population-based studies. Utility values are usually expressed on a scale ranging between 0 and 1 , where a higher value represents better HRQoL but it may result in a value lower than zero indicating a health state considered worse than dead. The utility values make it possible to calculate QALYs, which are essential in health economic evaluations of health care interventions [18]. As utility values for the EQ-5D-5 L were not yet available at the time of analysis, a Danish value set, developed by the EuroQol group, was used to transform values from the EQ-5D-3 L to the EQ-5D-5 L version [28].

In the EQ-VAS part, patients were asked to indicate their present health state on a vertical scale, numbered from 0 to 100 , where 100 is "the best imaginable health state" and zero "the worst imaginable health state".

\section{Data analysis and statistical methods}

Data analyses of background information and subgroup analyses of HRQoL outcomes were performed using descriptive statistical methods, using mean values, standard deviations (SD) and proportions.

The AKQoL, DLQI, and EQ-5D-5 L values were analyzed overall and for subgroups of patients depending on sex, age-groups (<60,60-69, 70-79 and $\geq 80)$, current AK at study visit, clinically suspected NMSC, lesion/s in the face, current comorbidities, current AK treatment, immunosuppressive treatment, and previous SCC or not. In addition, analyses of HRQoL in subgroups of patients with severe actinic damage or not was performed.

Statistically significant differences between categorical subgroups were tested with Wilcoxon rank-sum test (Mann-Whitney U test). For age groups a Kruskal-Wallis test was used, which is an extension of the Wilcoxon rank-sum test to several groups. Non-parametric tests were chosen as the HRQoL outcomes were not normally distributed.

Correlations between instruments were tested with the Spearman correlation test to investigate whether there was a relationship between them. The Spearman correlation test gives an absolute value between 0 and 1 , where 0 indicates no correlation and 1 indicates perfect correlation. The relationship could be positive or negative. A high EQ-5D-5 L or EQ-VAS value means good HRQoL, whereas a high score on DLQI or AKQoL indicates low HRQoL. Correlations between EQ-5D-5 L or EQ-VAS and DLQI or AKQoL therefore have negative values.

A multiple ordinary least squares (OLS) regression analysis with EQ-5D-5 L as the dependent or outcome variable was performed in order to investigate how EQ-5D-5 L was affected by age, sex, comorbidities, severe actinic damage, and clinically suspected NMSC. Reference group was man, no comorbidities, no severe actinic damage, and no NMSC. Only patients with current AK lesions were included in regression analysis.

A p-value lower than 0.05 was used as significance level in all statistical analyses. Statistical analyses were performed using Stata Statistical Software: Release 11.1. College Station, Texas, USA.

\section{Results}

\section{Patient characteristics and background}

Patient characteristics are presented in Table 1. A total of 312 patients were enrolled in the study. The majority of patients, $89 \%,(n=277)$, had current AK lesions at the study visit. The remaining 35 patients had attended control visits for previous AK. Of all patients, $80 \%$ had a pre-history of AKs and $42 \%$ suffered from recurrence of a specific AK lesion.

Sixty-seven percent were retired, $16 \%$ were working, $6 \%$ reported other activities and $11 \%$ did not report employment status. Comorbidities were reported in $66 \%$ of patients. The most common comorbidity was heart or vascular disease (26\%), followed by joint disease (22\%) and cancer $(21 \%)$. Nine percent were treated with immunosuppressive treatments.

A summary of the results from the different HRQoL instruments is shown in Table 2.

\section{The actinic keratosis quality of life questionnaire}

The mean AKQoL score for the 286 patients who completed the questionnaire was 6.7 (scale: 0-27). Patients 
Table 1 Patient characteristics

\begin{tabular}{lll}
\hline & $N$ & Percent \\
& 312 & 100 \\
\hline Women & 160 & 51 \\
Age, mean (SD) $^{\mathrm{a}}$ & $71(11.0)$ & \\
Immunosuppressive treatment $_{\text {Current AK lesion/s }}$ & 28 & 9 \\
Previously known AK & 277 & 89 \\
Previous AK treatment & 251 & 80 \\
Recurrent AK & 245 & 78 \\
Previous SCC & 130 & 42 \\
Previous BCC & 58 & 19 \\
\hline
\end{tabular}

SCC Squamous Cell Carcinoma, BCC Basal Cell Carcinoma

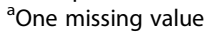

with severe actinic damage had worse HRQoL (10.07) than patients with no severe actinic damage (6.3) $(p<$ 0.001).Women reported higher AKQoL scores (7.9), i.e. worse HRQoL, than men (5.3) $(p<0.001)$. The scores also differed between age groups with patients younger than 60 years of age reporting worse HRQoL (8.1) compared to older patients (5.0-7.3) $(p=0.004)$. Patients with current AK reported better HRQoL (6.5) than patients without current AK (7.8) $(p=0.018)$.

The distribution between the different response levels was similar in the different domains function, emotions and control (Fig. 1). About $50 \%$ reported problems in each domain and in the single global item, $22 \%$ reported impairment in HRQoL.

\section{Dermatology life quality index}

The mean value for the 290 patients who completed the DLQI questionnaire was 1.99 (scale: 0-30). Patients with severe actinic damage had higher DLQI scores (4.6), i.e.

Table 2 Overall mean (SD) AKQoL, DLQI, EQ-5D-5 L, and EQ-VAS values and in subgroups of patients

\begin{tabular}{|c|c|c|c|c|c|c|c|c|c|c|c|c|c|c|c|c|c|}
\hline & & \multicolumn{4}{|c|}{ AK-QoL } & \multicolumn{4}{|l|}{ DLQI } & \multicolumn{4}{|c|}{ EQ-5D-5 L } & \multicolumn{4}{|c|}{ EQ-VAS } \\
\hline & & $n$ & Mean & SD & $p$-value & $n$ & Mean & SD & $p$-value & $n$ & Mean & SD & $p$-value & $n$ & Mean & SD & $p$-value \\
\hline Total population & & $286^{\mathrm{a}}$ & 6.7 & 4.8 & & $290^{b}$ & 1.99 & 2.71 & & $276^{c}$ & 0.884 & 0.140 & & 284 & 79.3 & 18.9 & \\
\hline \multirow[t]{2}{*}{ Sex } & Men & 137 & 5.3 & 3.7 & $<0.001$ & 138 & 1.73 & 2.46 & 0.121 & 132 & 0.901 & 0.127 & 0.060 & 136 & 81.3 & 17.9 & 0.086 \\
\hline & Women & 149 & 7.9 & 5.3 & & 152 & 2.23 & 2.91 & & 144 & 0.868 & 0.150 & & 148 & 77.6 & 19.7 & \\
\hline \multirow[t]{4}{*}{ Age groups $^{d}$} & $<60$ & 38 & 8.1 & 5.5 & 0.004 & 39 & 2.31 & 2.40 & 0.657 & 37 & 0.903 & 0.126 & 0.262 & 38 & 77.6 & 22.9 & 0.070 \\
\hline & $60-69$ & 103 & 6.6 & 4.7 & & 102 & 2.27 & 3.36 & & 98 & 0.895 & 0.134 & & 102 & 81.9 & 16.7 & \\
\hline & 70-79 & 86 & 7.3 & 4.7 & & 87 & 1.75 & 2.38 & & 84 & 0.888 & 0.139 & & 85 & 81.1 & 18.1 & \\
\hline & $\geq 80$ & 58 & 5.0 & 4.0 & & 61 & 1.70 & 2.04 & & 56 & 0.850 & 0.157 & & 58 & 73.7 & 20.2 & \\
\hline \multirow[t]{2}{*}{ Current AK } & Yes & 252 & 6.5 & 4.9 & 0.018 & 257 & 2.13 & 2.83 & 0.009 & 244 & 0.881 & 0.140 & 0.229 & 252 & 79.0 & 19.3 & 0.553 \\
\hline & No & 34 & 7.8 & 3.7 & & 33 & 0.91 & 1.04 & & 32 & 0.907 & 0.141 & & 32 & 82.2 & 15.5 & \\
\hline \multirow[t]{2}{*}{ Severe actinic damage $e^{e}$} & Yes & 27 & 10.07 & 5.6 & $<0.001$ & 27 & 4.59 & 4.07 & $<0.001$ & 26 & 0.844 & 0.139 & 0.068 & 27 & 70.2 & 22.3 & 0.012 \\
\hline & No & 259 & 6.30 & 4.5 & & 263 & 1.73 & 2.38 & & 250 & 0.888 & 0.147 & & 257 & 80.3 & 18.3 & \\
\hline \multirow[t]{2}{*}{ Suspected NMSC ${ }^{f}$} & Yes & 38 & 6.0 & 5.2 & 0.259 & 39 & 2.64 & 4.07 & 0.950 & 37 & 0.856 & 0.160 & 0.343 & 39 & 71.8 & 22.6 & 0.030 \\
\hline & No & 214 & 6.6 & 4.8 & & 218 & 2.04 & 2.54 & & 207 & 0.886 & 0.136 & & 213 & 80.3 & 18.4 & \\
\hline \multirow[t]{2}{*}{ Locations $^{f}$} & Face & 178 & 6.5 & 4.7 & 0.640 & 182 & 2.11 & 2.68 & 0.531 & 170 & 0.884 & 0.133 & 0.784 & 179 & 79.4 & 19.0 & 0.671 \\
\hline & $\begin{array}{l}\text { Non- } \\
\text { facial }\end{array}$ & 74 & 6.5 & 5.2 & & 75 & 2.19 & 3.17 & & 74 & 0.873 & 0.156 & & 73 & 78.0 & 20.1 & \\
\hline \multirow[t]{2}{*}{ Comorbidities $^{f}$} & Yes & 175 & 6.7 & 4.9 & 0.357 & 178 & 2.38 & 3.19 & 0.200 & 170 & 0.860 & 0.151 & $<0.001$ & 175 & 74.9 & 20.1 & $<0.001$ \\
\hline & No & 77 & 6.1 & 4.7 & & 79 & 1.57 & 1.64 & & 74 & 0.930 & 0.097 & & 77 & 88.1 & 13.4 & \\
\hline \multirow[t]{2}{*}{ Current AK treatment } & Yes & 125 & 7.0 & 5.6 & 0.402 & 127 & 2.43 & 3.38 & 0.186 & 120 & 0.900 & 0.130 & 0.221 & 123 & 78.2 & 20.3 & 0.609 \\
\hline & No & 74 & 5.8 & 3.7 & & 74 & 1.73 & 2.14 & & 72 & 0.870 & 0.150 & & 73 & 81.2 & 16.5 & \\
\hline \multirow{2}{*}{$\begin{array}{l}\text { Immunosuppressive } \\
\text { treatment }^{f}\end{array}$} & Yes & 25 & 7.2 & 6.0 & 0.869 & 25 & 4.04 & 4.46 & 0.023 & 23 & 0.876 & 0.143 & 0.900 & 24 & 70.6 & 25.1 & 0.061 \\
\hline & No & 227 & 6.4 & 4.7 & & 232 & 1.93 & 2.52 & & 221 & 0.881 & 0.140 & & 226 & 80.1 & 18.3 & \\
\hline \multirow[t]{2}{*}{ Previous SCC } & Yes & 53 & 8.0 & 6.6 & 0.410 & 54 & 3.4 & 4.4 & 0.016 & 51 & 0.849 & 0.153 & 0.038 & 52 & 70.8 & 21.4 & $<0.001$ \\
\hline & No & 233 & 6.4 & 4.2 & & 236 & 1.7 & 2.0 & & 225 & 0.892 & 0.136 & & 213 & 81.3 & 17.9 & \\
\hline
\end{tabular}




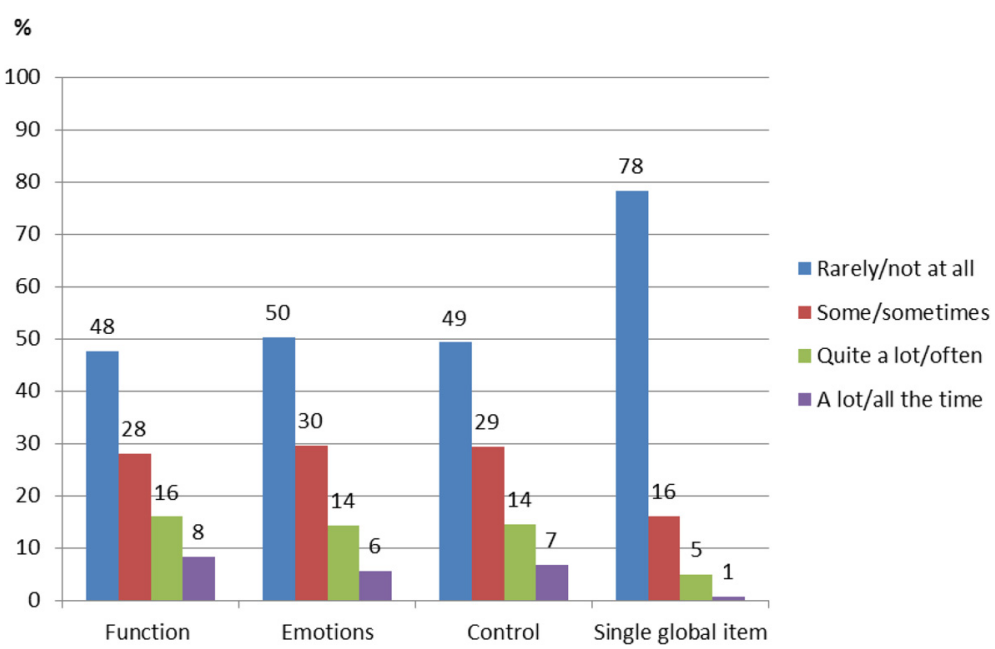

Fig. 1 The percentage of response levels in each domain of the AKQoL score. 26 questionnaires had more than one incomplete question. Six patients, out of the 286 , had one missing value only in one of the domains and were included in the analysis

worse HRQoL, than patients with milder AK (1.7) $(p<$ 0.001). Likewise, patients with current AK had higher DLQI (2.1) than patients with no current AK lesions (0.9) $(p=0.009)$. Patients with previous SCC had higher DLQI scores (3.4) than those without previous SCC (1.7) $(p=0.016)$ and patients treated with immunosuppressive treatments had higher DLQI scores (4) than patients who were not treated with such drugs (1.9) $(p=0.023)$. "Symptoms and feelings" was the DLQI dimension where most patients reported HRQoL impairment (37\%). The second most reported dimension related to the skin disease was "Daily activities" (25 \%) (Fig. 2).

\section{EQ-5D-5 L and EQ-VAS}

For the 276 patients who completed the EQ-5D-5 L questionnaire, the mean value was 0.88 (scale: $0-1$ ). Patients with comorbidities reported lower HRQoL (0.86) than those without comorbidities $(0.93)(p<0.001)$. Likewise, patients with previous SCC had lower HRQoL (0.85) than those without previous SCC $(0.89)(p=0.038)$. Patients reported most problems in the Pain/Discomfort dimension (38 \%) (Fig. 3).

The overall EQ-VAS value for 284 responding patients was 80 . For patients with severe actinic damage the corresponding value vas 70 .

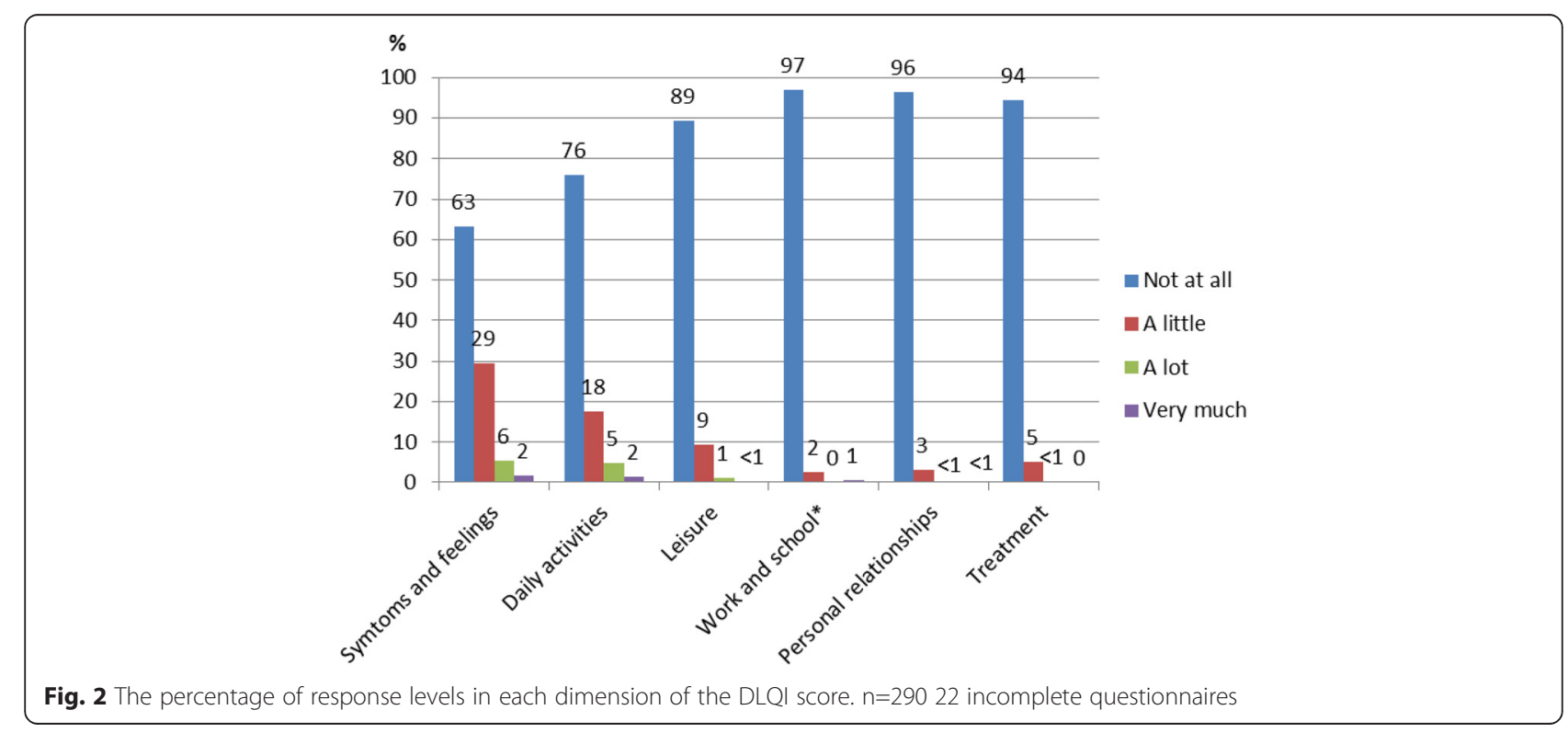




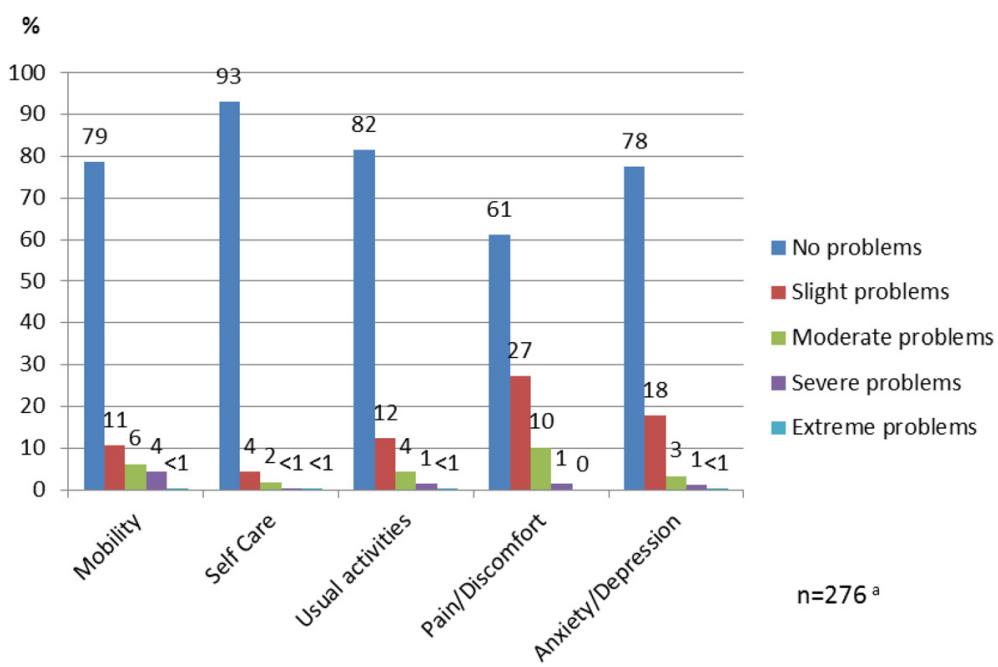

Fig. 3 The percentage of response levels in each dimension of EQ-5D-5 L. ${ }^{a} 36$ incomplete questionnaires

Correlations between instruments and regression analysis with EQ-5D-5 L as outcome

The correlations between the HRQoL instruments are presented in Table 3 . The analyses showed statistically significant correlations in all comparisons except between EQ-5D-5 L and AKQoL and between EQ-VAS and AKQoL. The correlation between DLQI and AKQoL was strongest, $0.52(p<0.001)$. This indicates that DLQI and AKQoL partly measure the same aspects of HRQoL. The correlation between EQ-5D-5 L and DLQI was weaker, $-0.36(p<0.001)$ but showing that there is a relationship between a higher EQ-5D-5 L value and a lower DLQI value. A similar correlation pattern, but weaker, was shown between EQ-VAS and DLQI, $-0.21(<0.001)$.

The regression analysis with EQ-5D-5 L as the dependent variable showed that $\mathrm{HRQ}$ oL decreased significantly with increasing age $(-0.002$ per year; $p=0.007)$, being a woman $(-0.039 ; p=0.026)$ and comorbidity $(-0.063 ; p=0.001)$.

\section{Discussion}

This observational, multi-center, cross-sectional study, showed that AK, especially severe actinic damage, has a negative impact on HRQoL, as measured by the AK and dermatology specific HRQoL instruments. This is demonstrated in several of the dimensions or domains

Table 3 Correlations between the HRQoL instruments, EQ-5D-5 L, EQ-VAS, DLQI, and AKQoL, tested with Spearman correlation test

\begin{tabular}{lcll}
\hline HRQoL instruments & Correlation & $p$-value & $N$ \\
\hline EQ-5D-5 L - DLQI & -0.36 & $<0.001$ & 273 \\
EQ-5D-5 L - AKQoL & -0.10 & 0.099 & 270 \\
EQ-VAS - DLQI & -0.21 & $<0.001$ & 282 \\
EQ-VAS - AKQoL & -0.01 & 0.859 & 278 \\
DLQI - AKQoL & 0.52 & $<0.001$ & 283 \\
\hline
\end{tabular}

in the different instruments and indicate that the disease specific and dermatological instruments capture different aspects of HRQoL.

To our knowledge, this is the first study where dermatologists have assessed the overall severity level of the AK disease in patients, rather than the severity grade in particular lesions only. Furthermore, it is the first study, to assess HRQoL with both generic and disease specific instruments in patients with AK. Results from all instruments showed more impaired HRQoL in patients with severe actinic damage than in those who were defined as having mild disease. The difference was statistically significant for AKQoL and DLQI.

The strength of this study is that patients can be considered representative for a dermatological population as they were included from different dermatology clinics in different parts of Denmark. A weakness of the study is that the sample in some subgroup analyses was limited, and may therefore limit the possibility of statistically significant results.

The only previously published study including the AKQoL questionnaire describes the development and validation of the questionnaire [14]. The mean AKQoL score in that study was 9.5 , which is similar to the score of 10.07 reported in the present study for patients with severe actinic damage. The AKQoL questionnaire is focused on the anxiety associated with sun damaged skin and the risk of developing a more serious disease. Contrary to what one would expect, patients with current AK lesions had lower impairment in AKQoL than patients with no current lesions. The reason for this may be that patients who previously have had lesions may still be worried about their skin as the risk of developing a new lesion is high [5]. The AKQol may therefore not be sensitive to change in clinical outcomes. Further evaluation and validation of the 
AKQoL questionnaire is needed before any recommendations about the usefulness of the instrument can be made.

DLQI is commonly used in dermatology studies [20, 22, 29-35], but we found only two studies including AK patients [24, 36]. In the first study DLQI was 1.95 for AK patients who received PDT with aminolevulinic acid and 1.38 for patients treated with imiquimod [36], in comparison to the mean value 1.99 for all patients and 4.59 for patients with severe actinic damage in the present study. In the second study DLQI varied from 1.6 prior to photodynamic therapy to 7.3 post treatment but was then normalized [24]. DLQI values between 2 and 5 could be interpreted as low effect on patient's life while values from 6 to 10 could be interpreted as having moderate effect [23]. In our cross-sectional study, there was no statistically significant difference in DLQI among patients who were currently in treatment and patients who had completed the treatment. More research is needed about how different treatment options affect patients HRQoL. Previous studies of patients with NMSC showed mean DLQI values of 2.4 and 4.9 [31, 32]. In observational studies of psoriasis and eczema DLQI ranged from 4.5 to $6.8[20,33,34]$. In a study of acne including a young population (mean age 22), the mean DLQI was 9.2 [35]. In comparison with other dermatological diseases such as NMSC, psoriasis and eczema, patients with severe actinic damage thus have similar HRQoL, but better HRQoL than young persons with acne.

EQ-5D has previously been used in a variety of studies of dermatologic conditions [20, 34, 35, 37-42], but we found no study of AK. The burden of disease varies between different skin conditions, with EQ-5D ranging from 0.43 in herpes zoster [40] to 0.84 in acne [35] and 0.85 in the mildest form of atopic dermatitis [39]. For severe actinic damage the mean EQ-5D value of 0.84 is similar to both acne and mild atopic dermatitis. The mean value of 0.88 in the overall patient group is similar to the 0.89 in the general Danish population [43]. A recent literature review of the use of EQ-5D in economic evaluations in dermatology included 20 studies identified between 2003 and 2011. The authors suggested that although the EQ-5D is broad enough to allow comparison between different diseases, it may not be specific enough to capture important aspects of HRQoL in dermatology [44].

One limitation of comparisons across results from different studies is that the patient populations might not be completely comparable regarding characteristics such as age, sex and co-morbidity. In the general population, women tend to report lower HRQoL than men and elderly lower HRQoL than younger age groups [43, 45]. In dermatology-specific HRQoL, however, younger individuals have reported lower HRQoL than older age groups [20]. This tendency can also be observed in our results, especially in the AKQoL instrument where the difference in HRQoL between patients younger than 60 years of age and older patients was statistically significant.

The correlation analyses suggest that the instruments EQ-5D-5 L, DLQI and AKQoL are complementary as they measure different aspects of the HRQoL. The magnitude of the correlation between DLQI and AKQoL, 0.52 , can be interpreted as moderate [46], while the correlations between the DLQI and EQ-5D-5 L, -0.36, and between DLQI and EQ-5D-5 L, -0.21 , can be interpreted as weak [46]. This is lower than previous findings of correlations -0.51 to -0.55 between EQ-5D-5 L and DLQI in patients with psoriasis $[20,34,41]$. There was no or little correlation between EQ-5D-5 L and AKQoL, which was expected as the EQ-5D captures overall HRQoL, and includes aspects beyond the impact of the skin.

The role of EQ-5D in economic evaluations in dermatology has been questioned as the EQ-5D is broad enough to allow comparison between different diseases, but it may not be specific enough to capture important aspects of HRQoL in dermatology [44]. Therefore, it is important to use both generic, dermatology- and disease specific HRQoL measure in dermatologic conditions such as AK.

The generic EQ-5D is important for health economic evaluations and it is essential as long as it is preferred by reimbursement authorities and policy makers for comparing costs and benefits across medical conditions [12, 13]. Moreover, generic instruments also measure comorbidities that go beyond conditions of the skin.

The DLQI is dermatology specific and is therefore more sensitive to detect changes in HRQoL related to clinical outcomes in dermatological conditions, which could be useful for regulatory authorities and for clinicians to individualize interventions and provide optimal care for patients. Moreover, as it is one of the most commonly used instruments in dermatology, the DLQI is appropriate for comparison with other skin diseases.

Whereas, the DLQI has been criticized of being too focused on physical limitations rather than the psychological impact of the skin [47], the AKQoL is focused on emotions and worries related specifically to sun damaged skin. The AKQoL captures domains of the HRQoL which are of relevance for persons with AK as they may worry about lesions developing to SCC. Furthermore, since the AK population is relatively old, some questions in the DLQI such as how much the skin caused problems in sports, work or school, and sexual relationships might be of less importance for an elderly population.

\section{Conclusions}

The EQ-5D-5 L, DLQI and AKQoL provide complementary information and are all useful, as they capture different aspects of HRQoL. Whereas the EQ-5D is essential for economic evaluations, the DLQI is responsive 
to change in relation to treatment and the AKQoL captures important features of the HRQoL that are specifically related to sun damaged skin. Future research is needed to further evaluate the responsiveness to change of the DLQI in relation to treatment and the AKQoL needs to be validated in future clinical studies.

The present study has shown that patients with severe actinic damage have impaired HRQoL, while patients with mild disease are less affected. HRQoL in patients with severe AK is similar to HRQoL in patients with psoriasis and eczema.

\section{Abbreviations}

AK: Actinic keratosis; AKQoL: Actinic keratosis quality of life questionnaire; BCC: Basal cell carcinoma; CRF: Case report form; DLQI: Dermatology life quality index; EQ-5D-5 L: EuroQoL five dimensions five levels; EQ-VAS: EuroQoL visual analogue scale; HRQoL: Health related quality of life; NMSC: Non-melanoma skin cancer; OLS: Ordinary least squares; PDT: Photodynamic therapy; QALY: Quality adjusted life years; SCC: Squamous cell carcinoma; SD: Standard deviation; VAS: Visual analogue scale.

\section{Competing interests}

Gunnel Ragnarson Tennvall and Jenny Norlin are employed at IHE and have no competing interest. Irena Malmberg is an employee of LEO Pharma AB. AM Erlendsson has received PhD Scholarship from LEO Pharma A/S. M Haedersdal received research grants from Almirall, Galderma International, Galderma Nordic and LEO Pharma.

\section{Authors' contributions}

GRT and JN participated in the design and coordination of the study, performed statistical analysis, participated in the interpretation and analysis of data, and drafting and revising the manuscript. IM, AM and MH participated in the design of the study and was involved in drafting and revising the manuscript. All authors have read and approved the final manuscript.

\section{Acknowledgements}

The authors wish to thank the Danish dermatologists who contributed to the data-collection: Anne Danielsen, Birgitte Stausbøl-Grøn, Bo Lasthein, Henrik Egekvist, Henrik Lorentzen, Henrik Thormann, Ida-Marie Stender, Niels Bech-Thomsen and Thomas Hohwy.

\section{Funding source}

This study was funded by LEO Pharma AB, Sweden.

\section{Author details}

'IHE, The Swedish Institute for Health Economics, P.O. Box 2127, SE-220 02 Lund, Sweden. ${ }^{2}$ LEO Pharma AB, Malmö, Sweden. ${ }^{3}$ Department of Dermatology, Bispebjerg Hospital, University of Copenhagen, Copenhagen, Denmark.

Received: 4 December 2014 Accepted: 26 June 2015

Published online: 29 July 2015

\section{References}

1. Dodson JM, DeSpain J, Hewett JE, Clark DP. Malignant potential of actinic keratoses and the controversy over treatment. A patient-oriented perspective. Arch Dermatol. 1991;127:1029-31.

2. Marks R, Rennie G, Selwood TS. Malignant transformation of solar keratoses to squamous cell carcinoma. Lancet. 1988;1:795-7.

3. Glogau RG. The risk of progression to invasive disease. J Am Acad Dermatol. 2000;42:23-4.

4. Marks R, Foley P, Goodman G, Hage BH, Selwood TS. Spontaneous remission of solar keratoses: the case for conservative management. Br J Dermatol. 1986;115:649-55.

5. Salasche SJ. Epidemiology of actinic keratoses and squamous cell carcinoma. J Am Acad Dermatol. 2000;42:4-7.

6. Frost CA, Green AC. Epidemiology of solar keratoses. Br J Dermatol. 1994;131:455-64.
7. Harvey I, Frankel S, Marks R, Shalom D, Nolan-Farrell M. Non-melanoma skin cancer and solar keratoses. I. Methods and descriptive results of the South Wales Skin Cancer Study. Br J Cancer. 1996;74:1302-7.

8. Memon AA, Tomenson JA, Bothwell J, Friedmann PS. Prevalence of solar damage and actinic keratosis in a Merseyside population. Br J Dermatol. 2000;142:1154-9.

9. Naldi L, Chatenoud L, Piccitto R, Colombo P, Placchesi EB, La Vecchia C. Prevalence of actinic keratoses and associated factors in a representative sample of the Italian adult population: Results from the Prevalence of Actinic Keratoses Italian Study, 2003-2004. Arch Dermatol. 2006;142:722-6.

10. Barr BB, Benton EC, McLaren K, Bunney MH, Smith IW, Blessing K, et al. Human papilloma virus infection and skin cancer in renal allograft recipients. Lancet. 1989;1:124-9.

11. Otuki MF, Reis RC, Cabrini D, Prudente AS, Horinouchi CD, Correr CJ. Patientreported outcomes in psoriasis research and practice. Br J Dermatol. 2011;165:1361-2.

12. NICE: Guideline Development Methods. 8 Incorporating health economics in guidelines and assessing resource impact. 2014. http://www.nice.org.uk/ niceMedia/pdf/GDM_Chapter8_0305.pdf Assessed 11 March 2014.

13. TLV. General guidelines for economic evaluations from the Pharmaceutical Benefits Board (LFNAR 2003:2). http://www.tlv.se/Upload/English/Guidelinesfor-economic-evaluations-LFNAR-2003-2.pdf2003.

14. Esmann S, Vinding GR, Christensen KB, Jemec GB. Assessing the influence of actinic keratosis on patients' quality of life: the AKQoL questionnaire. Br J Dermatol. 2013;168:277-83.

15. Gibbons E, Casanas i Comabella C, Fitzpatrick R. A structured review of patient-reported outcome measures for patients with skin cancer, 2013. Br J Dermatol. 2013;168:1176-86.

16. Lee K, Weinstock M. Prospective quality of life impact of actinic keratoses: observations from the veterans affairs topical tretinoin chemoprevention trial. Acta Derm Venereol. 2011;91:101-2.

17. Weinstock MA, Lee KC, Chren MM, Marcolivio K. Quality of life in the actinic neoplasia syndrome: The VA Topical Tretinoin Chemoprevention (VATTC) Trial. J Am Acad Dermatol. 2009;61:207-15.

18. Drummond MF, Sculpher M, Torrance G, O'Brian B, Stoddart G. Methods for the economic evaluation of health care programmes. New York: Oxford University Press; 2005.

19. Brooks R. EuroQol: the current state of play. Health policy. 1996;37:53-72.

20. Norlin JM, Steen Carlsson K, Persson U, Schmitt-Egenolf M. Analysis of three outcome measures in moderate to severe psoriasis: a registry-based study of 2450 patients. Br J Dermatol. 2012;166:797-802.

21. Ragnarson Tennvall G, Hjortsberg C, Bjarnason A, Gniadecki R, Heikkila H, Jemec GB, et al. Treatment patterns, treatment satisfaction, severity of disease problems, and quality of life in patients with psoriasis in three Nordic countries. Acta Derm Venereol. 2013;93:442-5.

22. Basra MK, Fenech R, Gatt RM, Salek MS, Finlay AY. The Dermatology Life Quality Index 1994-2007: a comprehensive review of validation data and clinical results. Br J Dermatol. 2008;159:997-1035.

23. Finlay AY, Khan GK. Dermatology Life Quality Index (DLQI)-a simple practical measure for routine clinical use. Clin Exp Dermatol. 1994;19:210-6.

24. Gholam P, Kroehl V, Enk AH. Dermatology life quality index and side effects after topical photodynamic therapy of actinic keratosis. Dermatology. 2013;226:253-9.

25. Olsen EA, Abernethy ML, Kulp-Shorten C, Callen JP, Glazer SD, Huntley A, et al. A double-blind, vehicle-controlled study evaluating masoprocol cream in the treatment of actinic keratoses on the head and neck. J Am Acad Dermatol. 1991;24:738-43.

26. Erlendsson AM, Egekvist H, Lorentzen HF, Philipsen PA, Stausböl-Grön B, Stender IM, et al. Actinic Keratosis: Disease characteristics and treatment patterns in Danish dermatology clinics - a cross-sectional study. Int I Dermatol. in press

27. EuroQol group. EuroQol-a new facility for the measurement of healthrelated quality of life. The EuroQol Group. Health Policy. 1990;16:199-208.

28. van Hout B, Janssen MF, Feng YS, Kohlmann T, Busschbach J, Golicki D, et al. Interim scoring for the EQ-5D-5 L: mapping the EQ-5D-5 L to EQ-5D-3 L value sets. Value Health. 2012;15:708-15.

29. Both H, Essink-Bot ML, Busschbach J, Nijsten T. Critical review of generic and dermatology-specific health-related quality of life instruments. J Invest Dermatol. 2007;127:2726-39.

30. Bronsard V, Paul C, Prey S, Puzenat E, Gourraud PA, Aractingi S, et al. What are the best outcome measures for assessing quality of life in plaque type psoriasis? A systematic review of the literature. J Eur Acad Dermatol Venereol. 2010;24 Suppl 2:17-22. 
31. Rhee JS, Matthews BA, Neuburg M, Smith TL, Burzynski M, Nattinger AB. Skin cancer and quality of life: assessment with the Dermatology Life Quality Index. Dermatol Surg. 2004;30:525-9.

32. Steinbauer J, Koller M, Kohl E, Karrer S, Landthaler M, Szeimies RM. Quality of life in health care of non-melanoma skin cancer - results of a pilot study. J Dtsch Dermatol Ges. 2011;9:129-35.

33. Badia X, Mascaro JM, Lozano R. Measuring health-related quality of life in patients with mild to moderate eczema and psoriasis: clinical validity, reliability and sensitivity to change of the DLQI. The Cavide Research Group. Br J Dermatol. 1999;141:698-702.

34. Hjortsberg C, Bergman A, Bjarnason A, Heikkila H, Hjelmgren J, Svensson A, et al. Are treatment satisfaction, quality of life, and self-assessed disease severity relevant parameters for patient registries? Experiences from Finnish and Swedish patients with psoriasis. Acta Derm Venereol. 2011;91:409-14.

35. Klassen AF, Newton JN, Mallon E. Measuring quality of life in people referred for specialist care of acne: comparing generic and disease-specific measures. J Am Acad Dermatol. 2000;43:229-33.

36. Hadley J, Tristani-Firouzi P, Hull C, Florell S, Cotter M, Hadley M. Results of an investigator-initiated single-blind split-face comparison of photodynamic therapy and $5 \%$ imiquimod cream for the treatment of actinic keratoses. Dermatol Surg. 2012;38:722-7.

37. Ghatnekar O, Ljungberg A, Wirestrand LE, Svensson A. Costs and quality of life for psoriatic patients at different degrees of severity in southern Sweden - a cross-sectional study. Eur J Dermatol. 2012;22:238-45.

38. Moberg C, Alderling M, Meding B. Hand eczema and quality of life: a population-based study. Br J Dermatol. 2009;161:397-403.

39. Poole CD, Chambers C, Sidhu MK, Currie CJ. Health-related utility among adults with atopic dermatitis treated with $0.1 \%$ tacrolimus ointment as maintenance therapy over the long term: findings from the Protopic CONTROL study. Br J Dermatol. 2009;161:1335-40.

40. Scott FT, Johnson RW, Leedham-Green M, Davies E, Edmunds WJ, Breuer J. The burden of Herpes Zoster: a prospective population based study. Vaccine. 2006;24:1308-14.

41. Shikiar R, Willian MK, Okun MM, Thompson CS, Revicki DA. The validity and responsiveness of three quality of life measures in the assessment of psoriasis patients: results of a phase II study. Health Qual Life Outcomes. 2006:4:71.

42. Weiss SC, Rehmus W, Kimball AB. An assessment of the cost-utility of therapy for psoriasis. Ther Clin Risk Manag. 2006;2:325-8.

43. Sorensen J, Davidsen M, Gudex C, Pedersen KM, Bronnum-Hansen H. Danish EQ-5D population norms. Scand J Public Health. 2009;37:467-74.

44. Pereira FR, Basra MK, Finlay AY, Salek MS. The role of the EQ-5D in the economic evaluation of dermatological conditions and therapies. Dermatology. 2012;225:45-53.

45. Burstrom K, Johannesson M, Diderichsen F. Swedish population health-related quality of life results using the EQ-5D. Qual Life Res. 2001;10:621-35.

46. Swinscow TDV, Campbell MJ. Statistics at square one. 10th ed. London: BMJ Books; 2002.

47. Nijsten T. Dermatology life quality index: time to move forward. J Invest Dermatol. 2012;132:11-3.

\section{Submit your next manuscript to BioMed Central and take full advantage of:}

- Convenient online submission

- Thorough peer review

- No space constraints or color figure charges

- Immediate publication on acceptance

- Inclusion in PubMed, CAS, Scopus and Google Scholar

- Research which is freely available for redistribution 